\title{
In-service Teachers' Geometry Content Knowledge: Implications for how Geometry is Taught in Teacher Training Institutions
}

\author{
Gladys Sunzuma ${ }^{1,2^{\star}}$, Aneshkumar Maharaj ${ }^{2}$ \\ ${ }^{1}$ Bindura University of Science Education, ZIMBABWE \\ 2 University of KwaZulu-Natal, SOUTH AFRICA \\ *CORRESPONDENCE: $\square$ gsunzuma@gmail.com
}

\begin{abstract}
The study intended to find out how in-service teachers were trained to teach geometry in Zimbabwe. Mixed method was employed in this study, in which qualitative and quantitative methods are concurrently used. While the questionnaire with closed ended questions constituted the quantitative aspect of the study, the open ended questionnaire questions and focus-group discussions were used for the qualitative aspect. The study participants consisted of 40 in-service teachers who completed the questionnaires and then participated in focus-group discussions. The findings reveal that 52.5 per cent of the teachers were adequately prepared to teach geometry and both teacher-centred and learner-centred approaches were used during their training. It emerged that teachers are likely to teach using the approaches that they experienced during their training. It is recommended that initial teacher training programs should adequately train teachers to teach geometry for them to be able to teach it effectively in schools.
\end{abstract}

Keywords: geometry, in-service teacher, teacher centred, learner centred, geometry content knowledge

\section{INTRODUCTION}

Geometry, which is one of the topics in the mathematics syllabus in Zimbabwe, helps learners to develop the skills of critical thinking, problem solving, conjecturing, deductive reasoning, logical argument and proof (Jones, 2002). Geometry taught in Zimbabwe is both algebraic and analytic. Algebraic as it involves matrix theory and analytic because it can be taught using the graphical approach. Geometric representations are useful in assisting learners to understand other topics of mathematics such as fractions and multiplication in arithmetic, the relationships between the graphs of functions, and graphical representations of data in statistics (Jones, 2002). Geometry appeals to visual, aesthetic and intuitive senses, which are intimately connected with the development of mathematics (Jones, 2002). Geometry is the most practical element of mathematics and teaching it appropriately can result in improved performance in mathematics (Jones, 2002).

Although geometry is perceived as a means for solving real-life issues and contributing to making mathematics an interesting subject, it is often avoided in the syllabus (Jones, 2002; Mashingaidze 2012). According to Healy and Hoyles (2000), Noraini (2009), Telima (2011) and Mashingaidze (2012), geometry is a difficult topic for teachers. Teachers tend to have a very low understanding of geometry (Mashingaidze, 2012). The Zimbabwe School Examination Council (ZIMSEC) examiners' report (2013; 2015) revealed that leaners' scored very low marks in geometry as compared to other mathematics topics. Reasons for poor performance in geometry include teachers' lack of geometry content knowledge and their teaching methods (Telima, 2011; Mashingaidze, 2012; Chiwiye, 2013). Teachers appear to have difficulties with their own content knowledge

Article History: Received 18 February $2019 \bullet$ Revised 18 April $2019 \bullet$ Accepted 20 April 2019

(C) 2019 by the authors; licensee Modestum Ltd., UK. Open Access terms of the Creative Commons Attribution 4.0 International License (http://creativecommons.org/licenses/by/4.0/) apply. The license permits unrestricted use, distribution, and reproduction in any medium, on the condition that users give exact credit to the original author(s) and the source, provide a link to the Creative Commons license, and indicate if they made any changes. 
in geometry (Mashingaidze, 2012). Teachers are required to teach geometry, yet they themselves may have done little geometry (Jones, 2000).

Teachers' geometry content knowledge is important in facilitating the learners' construction of knowledge. There has been much research on teachers' knowledge of mathematics that has focused on fractions (Carpenter, Fennema, Peterson, Chiang, \& Loef, 1988) or numbers and operations (Ball, 1990; Ma, 1999). The few studies on knowledge of geometry for teaching have consistently shown that geometry knowledge is generally problematic in terms of what teachers know and how they hold this knowledge of geometry, and it is essential to address this problem in teacher education (Jones, 2000; Ponte \& Chapman, 2006; Telima, 2011). These studies showed teachers' lack of ability to connect geometry to real-world situations and difficulty processing geometry information in addition to not having basic geometry knowledge, skills and analytical thinking ability. This study is intended to improve geometry teaching both in schools and teacher training institutions.

The purpose of this study was to explore how in-service teachers have been trained to teach geometry. The following research questions guided this study:

1. What are the teachers' views of their training in geometry teaching?

2. What approaches were used by their lecturers when teaching geometry?

It is hoped that determining how in-service teachers were trained can enlighten teacher educators on how to prepare teachers to teach geometry effectively.

\section{THEORETICAL FRAMEWORK AND LITERATURE}

\section{Pedagogical Content Knowledge}

Teachers need to possess geometry knowledge in order to teach effectively, which Shulman (1986) referred to as pedagogical content knowledge (PCK). Pedagogical content knowledge "also includes an understanding of what makes the learning of specific concepts easy or difficult: the conceptions and preconceptions that learners of different ages and backgrounds bring with them to the learning" (Shulman, 1986, p.9). Based on the social constructivist view of teaching, Cochran, DeRuiter and King (1993) renamed Shulman's PCK as pedagogical content knowing (PCKg) to acknowledge the dynamic nature of geometry knowledge development. Their model of pedagogical content knowledge comprised four key components: subject matter knowledge, pedagogy, learners' characteristics and the environmental context of learning. Cochran, DeRuiter \& King's (1993) model is based on constructivist perspectives and suggests that teacher educators should encourage trainee teachers to construct personal knowledge about how to teach geometry. Teacher educators can help trainee teachers build a deep understanding of geometry content from a teaching viewpoint that can be used to help particular learners to understand geometry, with teachers being active learners who tried to learn how learners construct geometry knowledge (Cochran, DeRuiter \& King, 1993).

\section{Knowledge of Geometry}

Teachers' knowledge of geometry comprises both knowledge of content that refers to skills, facts and concepts of the geometry syllabus, such as knowing what symmetry is, and knowledge of associations in geometry (Cochran, DeRuiter, \& King, 1993). Knowledge of associations can be explained in terms of how the specific content is associated with other concepts in geometry, mathematics and other subjects in the curriculum (Cochran, DeRuiter, \& King, 1993). In addition, the teaching of geometry requires the teachers to have an understanding of a number of mathematics topics, for instance, properties and construction of shapes, vectors, symmetry, cartesian equations and diagrams, similarity and congruency because its interdisciplinary in nature.

Monk (1994) believed that the number of mathematics courses done in a mathematics program makes a difference in teachers' knowledge, but only up to a certain point. The number of courses taken represents the required knowledge and can be used to measure the teachers' knowledge (Stedman, 2001). Monk (1994) reported that five courses in mathematics (no matter what the specific content) were the threshold beyond which few effects accrue. Ball, Lubieski and Mewborn (2001) noted that just counting the number of mathematics courses does not indicate whether teachers have the mathematical knowledge required for teaching. Ball, Lubieski and Mewborn (2001) focused on understanding of particular mathematical topics such as geometry rather than overall conceptions of mathematical knowledge. Researchers indicated that in-service 
teachers lack basic geometry content knowledge, expertise and critical thinking skill (Hershkowitz \& Vinner, 1984; Mayberry 1983).

\section{Knowledge of Teaching Geometry}

Teachers' knowledge of how the learners learn consists of the knowledge of their abilities and strategies, their developmental levels and the prior knowledge of geometry that they bring into the class (Cochran, DeRuiter, \& King, 1993). It also includes the misconceptions that the learners are likely to develop as well as understanding which concepts are easy or difficult to learn (Cochran, DeRuiter \& King, 1993). A teacher's knowledge of learners' learning processes also includes the ways that learners learn, use and come to understand a geometry concept and learners' diverse learning strategies and styles (Cochran, DeRuiter, \& King, 1993). However, Swafford, Jones and Thornton (1997) indicated that both the teachers and their learners exhibited similar patterns of geometry misconceptions.

\section{Knowledge of Instructional Strategies}

Teachers' knowledge of instructional strategies includes learning activities and use of teaching resources as well as representations such as explanations, examples, illustrations, and the sequencing of activities that facilitate learners' styles of understanding of geometry concepts (Cochran, DeRuiter, \& King, 1993). Geometric representations are useful in enabling the learners to make sense of other topics of mathematics such as graphical representations of data in statistics and multiplication in arithmetic (Jones, 2002). Geometric regions and shapes are beneficial for the development and understanding of fractional numbers, equivalent fractions, ordering of fractions and computing with fractions (Noraini, 2006).

In order for learners to acquire the desired geometry knowledge and skills it is important that the teachers to know how to teach geometry and be able to use a variety of teaching approaches that put more emphasis on problem solving, including real-life applications of geometry skills and enhancing learners' understanding of geometry concepts (Jones, 2002). Teachers' geometry content knowledge is important in facilitating the learners' construction of knowledge. Teachers should have geometry content knowledge that is adequate to enable them to facilitate the process of constructing knowledge in learners, come up with relevant examples and activities that direct the learning process, and facilitate learners' use of resources in the classroom. Nevertheless, several studies have shown that teachers' pedagogical content knowledge and geometry knowledge were insufficient (Barrantes \& Blanco, 2006; Clements \& Sarama, 2011; Hershkowitz \& Vinner, 1984). Barrantes and Blanco (2006) noted that the traditional teaching methods employed by teacher educators resulted in pre-service teachers not using diverse materials and sources when teaching geometry. As a result, learners made many errors in geometry problems. However, in contrast to the view that in teacher training institutions the mode of instruction is predominantly teacher-centred. Strickland (2008) noted other teaching approaches in her investigation of the practices of mathematics teaching, such as small groups, use of technology, lecture, whole-class discussion, learner presentations, working in pairs, inquiry, problem solving, proving, connections and communication. The teaching approach styles of the educators studied varied significantly. Therefore, it was necessary to find out how the teachers were trained to teach geometry.

\section{Knowledge of the Environmental Context of Teaching}

According to Cochran, DeRuiter and King (1993), teaching environments are affected by factors such as their political, social, cultural and physical environments. This includes the teachers' role in the geometry classroom, the use of resources from the local environment for teaching, class size, learners' socio-economic background, program, conditions in the classroom, and availability of time for teaching and learning (Rollnick, Bennett, Rhemtula, Dharsey, \& Ndlovu, 2008). It is essential for educators to view geometry as a practical subject and be able to provide learners with opportunities to use a variety of resources to discover and explore properties of shapes and geometry facts (Jones, 2002). However, research has revealed that the lack of availability of instructional materials and time to cover geometry concepts are among the factors responsible for learners' difficulty in understanding geometry concepts (Mashingaidze, 2012; Noraini, 2006; Telima, 2011).

According to Cochran, DeRuiter and King (1993), the four elements of PCKg must be acquired simultaneously, and teacher education programs must encourage integration by providing appropriate learning experiences to student teachers in order for them to concurrently experience all of the elements of PCKg and their complex interrelationships. It is essential to integrate the four categories from this model. For instance, learners working in groups may possibly signify knowledge about learners' learning, knowledge of the learning environment, and understanding of teaching strategies. 


\section{METHODOLOGY}

\section{Research Design}

In this study, the pragmatist paradigm was used as it acknowledges the use of multiple methods of gathering data in answering the research question and focuses on the real-world implications of the research (Cohen, Manion, \& Morrison, 2011; Creswell, 2015). The use of multiple methods is an important component in pragmatism as it enables errors in a single method to be rectified; meanings in data to be probed, corroborated and triangulated; and rich data to be collected (Cohen, Manion, \& Morrison, 2011). Pragmatists believe that research takes place in social, historical and other contexts (Creswell, 2015). This study focused on gaining a deeper understanding of how in-service mathematics teachers were trained to teach geometry. The study was a convergent mixed-method study that consisted of collecting, analysing and integrating quantitative and qualitative methods in a single study (Creswell, 2015). The merging of qualitative and quantitative methods provided a better understanding of how the in-service teachers were trained to teach geometry (Creswell, 2015).

\section{Participants}

The study was conducted among in-service mathematics teachers in their second year of study towards a Bachelor of Science Education Honours Degree in Mathematics at a university in Zimbabwe. The cohort consisted of $80 \mathrm{in}$-service mathematics teachers. In-service mathematics teachers were admitted into the university with a minimum teaching qualification, such as a diploma or certificate in education obtained from a teachers' college, and a minimum teaching experience of two years. These teachers had the requisite knowledge to teach of geometry since they were all trained to teach mathematics up to Ordinary Level. Stratified random sampling was used to select the 40 in-service teachers who completed the questionnaire. The same participants who completed the questionnaire were randomly selected for the five focus-group discussions. Each group had 8 teachers, 5 male and 3 female.

\section{Data Collection}

The data was generated through questionnaires and focus-group discussions. The questionnaire was comprised of both questions that used a Likert scale and open-ended questions. As a result, methodological triangulation where different data gathering methods were used on the same research questions was achieved. The data collected from the focus-group discussions complemented the quantitative data from the questionnaires by providing additional comprehensive information on the how in-service teachers were trained to teach geometry (Hennink, 2014). The data gathering instrument items were developed by the researchers. To ensure the content validity of the research instruments items, the instruments were given to the mathematics educators who are involved in instrument validation at the university under study. The questionnaires were self-administered by the researchers in a lecture room. A box was placed near the door of the lecture room where the participants would put the questionnaires. This was done to increase the response rate as well as for confidentiality purposes. The focus group discussions were done at the consecutively at the participants' convenient time. The focus group discussions were audio-recorded so that they could be replayed during the data analysis. This was done to enhance the validity and reliability of the findings. For the purposes of anonymity, the five groups were coded A, B, C, D and E.

\section{Data Analysis}

An inductive (Creswell, 2015) data analysis process, where codes were created by the researcher through direct interaction with the data, was used for qualitative data from both the questionnaires and focus-group discussions. The inductive analysis process involved coding and categorising data, identifying patterns and themes, as well as making logical conclusions (Curtis \& Curtis, 2011). The data from focus-group discussions and questionnaires were coded and gradually reduced into few important groups of major themes. Member checking was done in this study by taking the results to the participants for confirmation and validation purposes. SPSS software was used for frequency distribution analysis for the completed questionnaires. 
Table 1. Responses from the teachers who were trained to teach geometry $(n=40)$

\section{Representative quote}

I did not see or face any challenges when the topic was introduced to me.

I mastered the concepts and was aware of the problem areas.

I don't have any problems in teaching geometry concepts.

I have been well equipped with several approaches.

It's an interesting topic.

\section{RESULTS}

\section{Mathematics and Geometry Courses Taken during Training}

The data from closed-ended questionnaire questions showed that 62.5 per cent had taken mathematics courses during their teacher training. This was supported by the data from the open-ended questionnaire questions, which revealed that 70 per cent of the participants were taught geometric concepts during their teacher training programs. The data from the focus-group discussions also confirmed that teachers were taught geometry concepts during their teacher training, as the following teachers' extracts show:

Three courses with all the concepts such as statistics mechanics, pure mathematics. Two courses in mechanics and pure mathematics had geometry concepts. (Group A)

Eight courses, almost all the courses had an element of geometry. (Group B)

Four courses for 2 years, two courses had geometry concepts. (Group C)

Ten courses, two had geometry concepts. (Group D)

Ten courses, three had geometry concepts. (Group E)

The geometry courses were taught by content experts, in other words, lecturers or tutors from the mathematics department of the institution. From the above statements, Groups D and E had the highest number of mathematics courses at 10; followed by Group B with eight; Group C with four; and Group A with three, which was the least. Geometry concepts were taught in as few as two mathematics courses (Groups A, $\mathrm{C}$ and $\mathrm{D})$ and as many as eight (Group B).

However, the results show that there are inconsistencies in how the teachers view the ways they were trained to teach geometry. The following two sub-themes are discussed below: adequate teacher training in geometry and inadequate teacher training in geometry.

\section{Adequate Teacher Training in Geometry}

The data from open-ended questionnaire questions showed that 52.5 per cent of the teachers were adequately prepared to teach geometry. Their responses are shown in Table 1.

The teachers indicated that they did not have any problems when teaching geometry (see Table 1). This was supported by the data from the focus-group discussions, which showed that the teachers from Groups A, $\mathrm{B}$ and $\mathrm{C}$ were prepared to teach geometry during their training or professional development. A statement representative of Groups A, B and C was presented by Group B:

Yes, we were trained to teach geometry. We were trained to use teaching aids and charts and to draw shapes using mathematical instruments. (Group B)

Teachers from Groups A, B and C reported that they were trained to teach geometry. This data was further supported by the teachers' responses from open-ended questionnaire questions concerning the coverage of geometry content during training, where 45 per cent indicated that it was adequate. The reasons mentioned by the teachers whose lecturers taught geometry-related areas of the curriculum adequately were classified into two categories: adequate coverage of the syllabus without linking to culture (see Table 2) and adequate coverage of the syllabus with a linkage to culture and practical examples, as shown in Table 3. 
Table 2. Adequate coverage of geometry content without linking to culture $(n=40)$

\section{Representative quote}

Almost all areas were covered in the course outline.

Used methods that made me answer examination questions.

Linked the concepts well to the demands of the syllabus.

General geometry was covered.

The lecturer managed to cover all concepts highlighted in the syllabus.

It was according to the curriculum leading to maximum understanding.

Only used chalk-board and textbook through demonstration.

Lecturers did not link geometry concepts to culture or environment.

Just used geo tools and did not explain how we used them to arrive at the final answers rather deeper understanding as it demands.

Table 3. Adequate coverage of the syllabus with a linkage to culture and practical examples $(\mathrm{n}=40)$

\section{Representative quote}

We were given a project of making geometrical instruments using locally available materials for use in the class in the event that you would be deployed in a remote school without resources.

Very well and practical examples were given.

Practical examples were done.

Linked syllabus requirements and culture.

Table 4. Lecturers' practices $(n=40)$

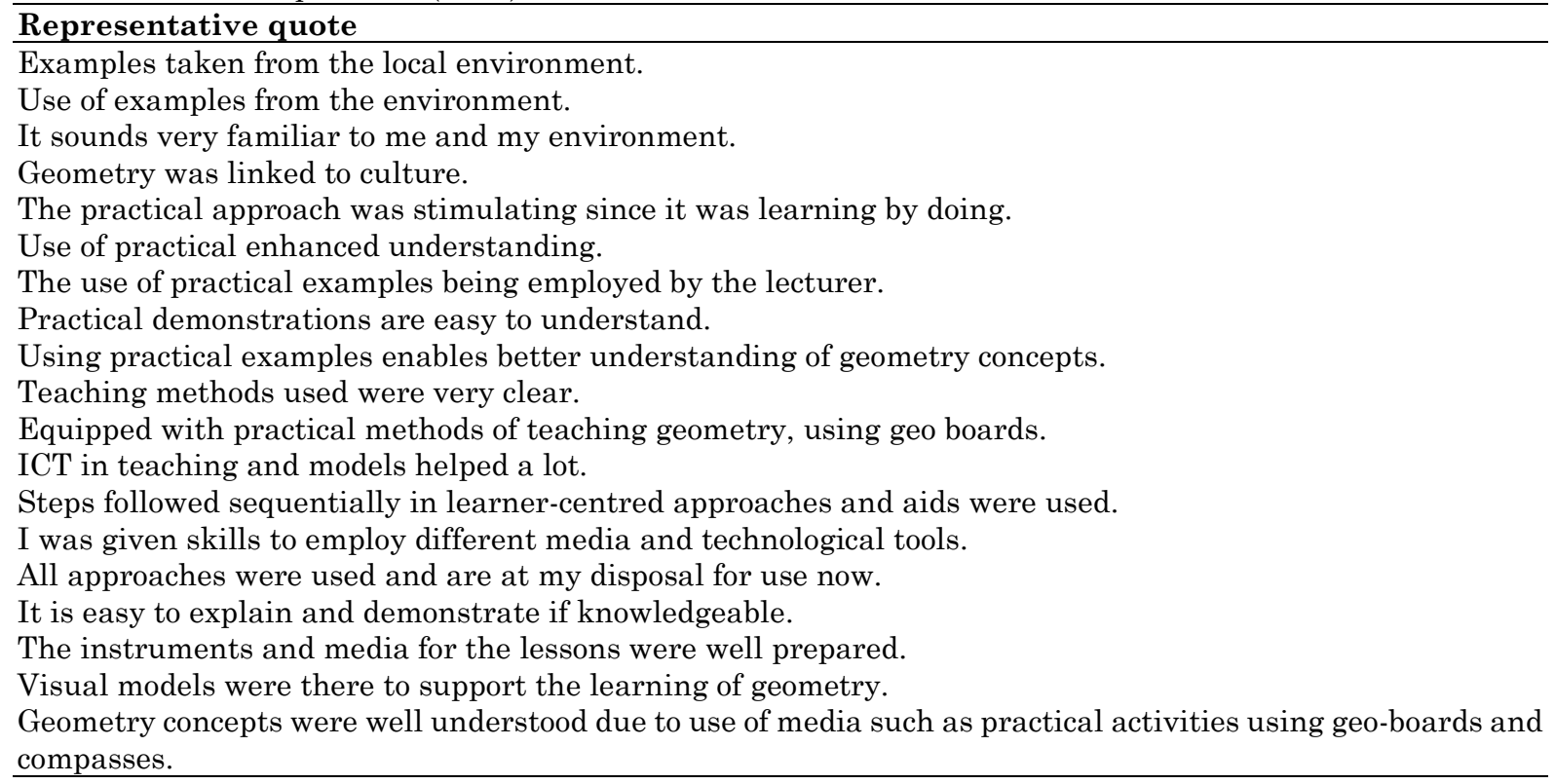

Some of the teachers (see Table 2) felt that they adequately covered the syllabus, but their learning of geometry concepts was not related to their cultural activities or experiences. All the geometry concepts were covered using approaches that would enable the teachers to answer examination questions.

Some teachers (see Table 3) felt that their adequate coverage of the syllabus was complemented with a linkage to cultural and practical examples. In this study, the idea of connecting geometry to cultural examples could be one of the reasons for the teachers' adequate training in geometry.

\section{Teachers' Reasons for not Facing Difficulties in Understanding Geometry Concepts}

The data from open-ended questionnaire questions showed that 60 per cent of the teachers did not face difficulties in understanding the geometry concepts. Their reasons for not facing difficulties in understanding geometry concepts during their teacher training programs were coded as lecturers' practices (see Table 4), sufficient resource (see Table 5), lecturers' geometry content knowledge (see Table 6) and the interdisciplinary nature of geometry, as shown in Table 7. 
Table 5. Sufficient resources $(\mathrm{n}=40)$

Representative quote

Very few to no challenges because resources are natural and easily/readily available.

Table 6. Lecturers' geometry content knowledge $(\mathrm{n}=40)$

Representative quote

The lecturer had adequate knowledge and was very skilful.

Table 7. The interdisciplinary nature of geometry $(n=40)$

Representative quote
It integrates well with other mathematical concepts, such as properties and construction of shapes, vectors
and matrices.

Lecturer's practices can influence how learners learn and understand geometry concepts. The results show that the lecturers' practices helped the teachers understand the geometry concepts. The teachers attributed their adequate training in geometry to learner-centred approaches such as practical teaching methods and the use of media and geometry instruments that helped in their understanding of geometry concepts. In addition, geometry concepts were linked to the cultural and environmental backgrounds of the teachers.

Teachers (see Table 5) indicated that geometry resources were sufficient because the resources were natural and locally available. This was supported by teachers from Group B, who felt that they had enough resources to consolidate their geometry understanding. Teachers from Group B said:

At college we had enough materials. (Group B)

Their response about content sources available to them on the topic of geometry indicated that that they had had enough activities to consolidate concepts taught.

It was acknowledged that the lecturers' had adequate geometry content knowledge as indicated in Table 6. The responses of the participants indicated that they felt that adequate geometry knowledge helped their lecturers to understand how they acquire knowledge and to develop geometry activities based on their cultural experiences that support their understanding of geometry concepts.

The findings in Table 7 show that geometry integrates well with other mathematics topics which concurs with Jones (2002) who pointed out that geometry is related to other mathematics topics. Geometry is of great importance in a wide range of topics in mathematics.

The data from the focus-group discussions also supported the teachers' views from the open-ended questionnaire questions that those teachers did not have difficulties with geometry concepts. Teachers from Groups A, B and C indicated that they did not have any difficulties with geometry concepts. This was supported by the following statements from the focus-group discussions:

No, we don't have any problems with geometry. At our level, no, we think we are trying our best. (Group A)

For the level that we are currently teaching, that is, 'O' Level, we don't have any problems. (Group B)

No we don't have any problems. (Group C)

These comments further support the questionnaire data showing that these teachers did not have any challenges when teaching geometry. The teachers were able to use their geometry knowledge for decision making, choosing teaching approaches, and preparing for the teaching and learning activities they use in class.

Furthermore, the data from the focus-group discussions showed that some teachers (20\%) were even capable of teaching geometry up to 'A' Level, asking what is new about teaching geometry at that level, as can be seen from the group's response:

Very much. Yes, we are competent: We can teach even up to 'A' level; what's new? (Group B) 
Table 8. Responses from the teachers who were inadequately prepared to teach geometry $(\mathrm{n}=40)$

\title{
Representative quote
}

I lacked the key needs required to teach geometry.

Not enough knowledge was acquired during my training.

Less knowledge on teaching geometry.

Lack understanding of geometry concepts.

Some of the concepts were not even taught, for instance, transformation.

Table 9. Partial coverage of geometry content $(n=40)$

\section{Representative quote}

Not all concepts were covered.

The lecturers did not have enough time to cover all the geometry concepts.

The lecturer dealt with issues that were familiar to him.

Time factor: The lecturer just gave only an introduction to geometry.

Some of the concepts like transformation were not taught.

From these comments it seems these teachers were overconfident in terms of their knowledge base. It indicates that they were positive and ready to teach geometry because teaching content was not a problem to them. They claimed that they were competent in teaching geometry.

Some of the teachers felt that they were competent to teach geometry to the level that they were teaching, the 'O' Level, which was the level they were trained to teach. This was supported by the following statements from the focus-group discussions:

\author{
Yes, we are competent to teach geometry; it also depends with the level for the ' $\mathrm{O}$ ' Level we \\ are comfortable. (Group A) \\ Yes we are competent; it is practical, hands-on activity. (Group C)
}

The comments illustrate an emphasis on the practical aspect of teaching geometry. According to what they said, these teachers seemed to be confident.

\section{Inadequate Teacher Training in Geometry}

It is possible that teachers' deficiency in geometry content would affect the teaching and learning of geometry concepts. The data from open-ended questionnaire questions showed that 47.5 per cent of the teachers were not adequately prepared to teach geometry; hence their geometry content knowledge for teaching was inadequate, as shown in Table 8.

Teachers reported that they lacked knowledge on geometry (see Table 8), signifying that were not adequately trained to teach geometry. Teachers' lack of geometry content knowledge was also supported by the data from open-ended questionnaire questions and focus-group discussions on partial coverage of geometry concepts and those who were never taught geometry concepts.

Data from open-ended questionnaire questions showed that 40 per cent of the teachers felt that their lecturers only partially taught the geometry-related areas of the syllabus; their responses are shown in Table 9.

Data from the focus-group discussions supported the partial coverage of geometry content during teacher training. This is what teachers from Group D said:

Not prepared to teach geometry concepts such as transformation because teachers skipped the topic. Lecturers themselves don't understand it, maybe they were not teaching it because they themselves too were never taught. Transformation was skipped so we will skip it too because we don't know what to teach. (Group D)

The teachers pointed out that geometry was not adequately covered; for instance, they pointed out that they were going to skip the concepts of transformation that were also skipped during their own training.

Data from open-ended questionnaire questions indicated the 15 per cent of the teachers felt that their lecturers never taught the geometry-related areas of the syllabus; their responses are shown in Table 10. 
Table 10. Never taught geometry concepts $(n=40)$

\title{
Representative quote
}

Not familiar with the concepts.

We were never taught the areas of the syllabus concerning geometry.

Not formally part of the syllabus.

Table 11. Lectures' practices $(n=40)$

\section{Representative quote}

Teaching methods used were not clear to understand geometry concepts.

I still face challenges to deliver since l was taught using a demonstration method.

My teacher never explained clearly and in detail.

There were no examples made by the teachers during lessons, for instance, relating to our real life.

Teachers forced me to regurgitate or memorise without deriving them for me to see where the concept is coming from.

Simply followed what the lecturer asked us to do.

Geometry content was from the syllabus only.

Table 12. Insufficient resources $(n=40)$

\author{
Representative quote \\ Lack of resources. \\ Time and resources were scarce. \\ Because of the time factor, it was not enough. \\ Geometry needs more time.
}

Data from focus-group discussions also confirmed that a few teachers were never taught geometry concepts either during secondary school or their teacher training period, as the following teacher's extract shows:

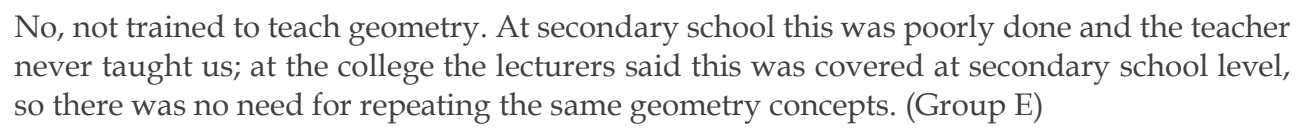

The teachers pointed out that they were never taught geometry concepts during their training. This may indicate that these teachers have little or no experience and knowledge of their own on which to base or develop geometry teaching activities.

\section{Teachers' Difficulties in Understanding Geometry Concepts}

The teachers who were not adequately trained to teach geometry also had some challenges in understanding geometry concepts. Data from open-ended questionnaire questions showed that 40 per cent of the participants had difficulties in understanding geometry concepts during teacher training. Their reasons for facing difficulties in understanding geometry concepts were categorised as lecturers' practices (see Table 11) and insufficient resources, as shown in Table 12.

Lecturers' practices involve the way they interact with the learners and the teaching approaches they use. The teachers considered how they were taught by their lecturers to be responsible for their difficulty in understanding geometry concepts and for their inadequate training to teach geometry (see Table 11). The approaches used involved learning through memorisation and rote learning, which are methods based on traditional views of teaching. Some of the teachers pointed out that their lecturers did not link geometry teaching and learning to cultural examples and experiences. Geometry knowledge learned through memorisation is limited and shallow, which could eventually lead to difficulty in understanding geometry concepts and ultimately limited geometry content knowledge.

Some of the teachers (see Table 12) felt that they had insufficient resources and time. In most instances where time is a scarce resource, lecturers tend to rush to cover the syllabus, and in doing so they employ traditional methods that make it faster to complete the syllabus. The data from the focus-group discussions confirmed that the teachers did not have enough geometry resources during their training. The teachers from Groups A, C, D and E felt that they did not have enough resources to consolidate their understanding of geometry as represented in their voices below. 
No, we didn't have enough geometry resources, and also the time did not allow us to do much. Lecturers did not have adequate knowledge on geometry. (Group A)

We lacked modern visual aids and models and also we lacked field trips in geometry. (Group C)

No, we didn't have enough resources in geometry. (Group D)

The teachers from Group A reported that their lecturers lacked geometry content knowledge. This made it challenging for them understanding geometry and how they would approach it in their own teaching in schools.

\section{Teachers' Views of their Lecturers' Instructional Practices in Geometry Courses}

The teaching approaches employed in teacher training programs were important to this study because they point to how the teachers were trained and also determine the way the teachers would teach geometry in schools. Two categories of approaches that their lecturers used were identified from their explanations: learner-centred approaches and teacher-centred approaches.

Data from the closed-ended questionnaire questions showed that 55.5 per cent disagreed or strongly disagreed that geometry concepts were taught using traditional approaches during their teacher training. This indicates that other teaching approaches such as the learner-centred approaches could have been employed during their teacher training program.

On the other hand, data from the open-ended questionnaire questions showed that 43 per cent of the participants were taught geometry concepts through learner-centred approaches such as guided discovery methods, problem-based learning and project-based methods. In addition, the study revealed that the lecturers made use of teaching aids such as wire models, geo boards and visual aids.

The lecturers also used real examples whereby the lecturer could link theory to practical experience; for instance, in rural areas, a goat tied to a tree with a rope can walk around the tree with the rope fully extended to make a circle with a radius equal to the length of the rope. The teachers also indicated that case studies and practical approaches were also employed by their lecturers in the teaching of geometry, and they referred to these approaches as learning by doing with the use of real objects.

Data from the focus-group discussions also confirmed that their lecturers used learner-centred approaches when teaching geometry. For example, teachers from Groups B and D said:

We were exposed to a practical approach. Practical is very important and helpful in understanding geometry. (Group B)

Discovery learning was used by our lecturer. We were given tasks to work on and encouraged to research. (Group D)

The use of learner-centred approaches may have helped the teachers in understanding the geometry concepts and later on enabled them to relate geometry to cultural examples and activities in their teaching. Engaging the learners in all the geometry learning activities may result in meaningful construction of knowledge that stimulates them in learning geometry.

The data from the open-ended questionnaire questions showed that 57 per cent of the teachers were taught geometry concepts during teacher training programs through traditional approaches such as the lecture method and the demonstration method. This was supported by the data from the focus-group discussions where teachers from Groups A and C said:

Abstract teaching, it is only now that we understand some of the concepts. (Group A)

Use of formulas, abstract concepts, formula approaches rather than a practical approach was used. It was too theoretical from the lecturer, bookish and examination oriented, that is why our learners do not like geometry, because of the way we teach. We teach in the same manner we were taught and our learners cannot apply geometry in daily life so they say geometry is not relevant in their life. (Group C)

The above comments indicate that the teaching approaches involved the use of formulas and the teaching was also abstract. The lecturers' role was that of informing the learners with the learners being passive, which 
demotivates the learners. Learners are likely to memorise and reproduce what they have learnt from their lecturers for the purposes of passing examinations. It also emerged that the teachers teach in the same way that they were taught.

\section{Instructional Approaches in Pedagogics Courses}

The pedagogics courses were taught by lecturers or tutors from the education department of the institution. The teachers would go for teaching practice for a year in schools of their choice after passing the pedagogics courses. During teaching practice, the teachers were supervised by lecturers from the education department. The teachers' responses show that they have all done some pedagogical courses: Group A had taken six, the highest number of courses; Group B and E each had taken five; Group C had taken three; and Group D had taken one, the least number of courses. Two categories of teaching approaches that were used during pedagogics courses teacher training programs were identified: learner-centred approaches and teachercentred approaches.

Teachers from all the groups mentioned that they were involved in learning communities such as peer learning, group learning and group presentations. A statement representative of all the groups was presented by Group B teachers:

We had tutorial groups and peer teaching for specific subjects where we would criticise one another. (Group B)

During peer teaching and group presentations, the students had opportunities to ask questions and be involved in meaningful discussions where they were free to contribute and discuss issues in pedagogy from a mathematical point of view.

Within the category of teachers who said that they were taught pedagogic courses using teacher-centred approaches, an example of such methods was the lecture method mentioned by the participants from all groups where the lecturer or tutor transmits knowledge to the learners who try to receive and keep it. A representative statement of all the groups was presented by Group C teachers:

A lecture method was employed. What we call mass lecture involving all of about 200 preservice teachers from all the different subjects. The group was just too large. (Group C)

It was noted that in this study, the reason for using the lecture method may have been the large class size, which was about 200. This very high ratio of student teachers to lecturers and tutors in teacher training programs in Zimbabwe has made it difficult for lecturers and tutors to employ learner-centred approaches.

\section{DISCUSSION, CONCLUSION AND RECOMMENDATION}

The purpose of the study was to find out how in-service mathematics teachers were trained to teach geometry. The findings of the focus-group discussions reinforce those of the questionnaire on courses taken in geometry. As highlighted by the findings, teachers from Groups B, D and E meet the requirement of five courses, in line with Monk (1994). On the other hand, the teachers from Groups A and C could not meet this criterion. In this study, focus fell on the understanding of a particular mathematics topic, geometry, rather than on global conceptions of mathematical knowledge, in line with Ball, Lubieski \& Mewborn (2001). The majority of the teachers had taken at least one course in geometry. It is essential that teachers have a good background in the geometry they teach in order to be able to teach it effectively.

The findings from the questionnaires and focus-group discussions showed that some of the teachers (52.5\%) viewed their training as adequate. Their reasons for feeling that they had been adequately trained were the interdisciplinary nature of geometry, lecturers' practices, adequate coverage of the syllabus without linking to culture, adequate coverage of the syllabus with a linkage to culture and practical examples, and sufficient resources (see Table 1). The findings reveal that teachers' adequate training in geometry was due to the fact that geometry was related to other areas of mathematics, hence it was not taught as an independent topic.

In addition, the findings show that lecturers using teaching approaches that were based on social constructivism, such as the use of practical activities, media and visual models, may have enhanced the teachers' understanding of geometry concepts. Hands-on geometry activities are essential elements that embrace Jones' (2002) view that geometry is a practical subject. The adequate coverage of the syllabus with a 
linkage to culture and practical examples is in line with the Zimbabwean mathematics syllabus (2015), which encourages the teaching of geometry to be connected to the learners' interests and culture or environments.

The findings also show that geometry was adequately covered without connecting it to the learners' own culture. The teaching of geometry tends to be textbook based without examination of the learners' immediate environment (Jones, 2002). The findings in this study reveal that very few teachers had sufficient geometry resources during their training. The finding contradicts the view held by Jones (2002) that geometry should be considered a practical subject that requires learners to use a variety of resources to investigate and explore the properties of shapes and geometry facts.

The study also showed that some teachers (47.5\%) were inadequately prepared to teach geometry because they lacked geometry content knowledge (see Table 4). The findings coincide with earlier findings by Jones (2000), Ponte and Chapman (2006) and Telima (2011) on teachers' lack of geometry knowledge. The teachers blamed their lack of geometry knowledge on either partial (see Table 5) of lack of coverage of geometry concepts (see Table 6) during training and at the secondary school level as well as lecturers' practices and insufficient resources (see Table 7). The findings showed that some geometry concepts were skipped during teacher training. This is similar to Mashingaidze's (2012) finding that geometry concepts were skipped or never taught because lecturers themselves do not understand the concepts. The partial or lack of coverage of geometry concepts makes it difficult for teachers to teach geometry effectively. Jones (2002) reported that teachers are expected to teach geometry effectively yet they had little experience with geometry. Geometry in most cases is neglected (Jones, 2002). In order for teachers to be capable of teaching efficiently, they must possess adequate geometry content knowledge.

Furthermore, the findings revealed that some teachers had difficulties with geometry concepts during their training. Their reasons for facing difficulties with geometry concepts were lecturers' practices and insufficient resources (see Table 7). The study findings show that the lecturers' practices include an over-reliance on the syllabus and that a teacher-centred approach was used that involved memorising concepts, which does not result in a deeper understanding of geometry concepts and does not encourage the application of these concepts in real-life situations. The lecturers' approaches of teaching contributed to the teachers' difficulty in understanding geometry concepts (Mashingaidze, 2012; Noraini, 2006; Telima, 2011). In addition, some of the teachers in the universities felt that resources were insufficient, including a lack of time, which may result in topics such as geometry not being covered (Mashingaidze, 2012; Noraini, 2006; Telima, 2011).

The findings revealed that teacher-centred approaches were used during their training in both geometry and pedagogy courses. The finding is similar to earlier findings by Barrantes \& Blanco (2006), who reported that teacher training programs put more emphasis on predominantly teacher-centred procedural learning and skills. Furthermore, the teachers reported that learner-centred approaches were used by their lecturers in teaching geometry and pedagogy courses during their training. In addition, teachers reported that they were going to teach geometry in the way that they were taught, which is in line with Ferner's (2013) study, which showed that teachers usually teach in the manner they were taught.

The findings reveal that the pedagogy courses were taught in the education department and the geometry courses in the mathematics department. Basing on this finding, it could be argued that the teacher training program did not integrate the four components from Cochran, DeRuiter and King's (1993) model. This leaves the teachers to integrate these four components own their own during a one-year period of teaching practice, which was supervised by lecturers from the education department.

It is disappointing to note that some teachers (47.5\%) were not adequately trained to teach geometry concepts, yet they are expected to teach the concepts in schools. It is worrisome that teachers who were taught using teacher-centred approaches would be doing exactly the same with their learners. It is hoped that initial teacher training programs will focus on adequately training teachers in geometry concepts and on using learner-centred approaches during the training period. There is need for continuous teacher development in geometry concepts through workshops. One of the limitation of this study is it focussed on geometry and second year in-service teachers only. A more comprehensible research can be conducted with different samples and topics in mathematics.

\section{Disclosure statement}

No potential conflict of interest was reported by the authors. 


\section{Notes on contributors}

Gladys Sunzuma - Bindura University of Science Education, Zimbabwe and University of KwaZuluNatal, South Africa.

Aneshkumar Maharaj - University of KwaZulu-Natal, South Africa.

\section{REFERENCES}

Ball, D. L. (1990). The mathematical understandings that prospective teachers bring to teacher education. Elementary School Journal, 90 (4), 449-466. https://doi.org/10.1086/461626

Ball, D. L., Lubieski, S., \& Mewborn, D. (2001). Research on teaching mathematics: The unresolved problem of teachers' mathematical knowledge. In V. Richardson (Ed.), Handbook of research on teaching. New York: Macmillan.

Barrantes, M., \& Blanco, L., J. (2006). A study of prospective primary teachers' conceptions of teaching and learning school geometry. Journal of Mathematics Teacher Education, 9, 411-436. https://doi.org/10.1007/s10857-006-9016-6

Carpenter, T. P., Fennema, E., Peterson, P. L., \& Carey, D. A. (1988). Teachers' Pedagogical Content Knowledge of Students' Problem Solving in Elementary Arithmetic. Journal for Research in Mathematics Education, 19(5), 385-401. https://doi.org/10.2307/749173

Chiwiye, T. (2013). Assessment of mathematics and science subjects in Zimbabwe: ZIMSEC Perspective, ZimSEC, Harare.

Clements, D., \& Sarama, J. (2011). Early childhood teacher education: The case of geometry. Journal of Mathematics Teacher Education, 14, 133-148. https://oi.org/10.1007/s10857-011-9173-0

Cochran, K. F., DeRuiter, J. A., \& King, R. A. (1993). Pedagogical content knowing: An integrative model for teacher preparation. Journal of Teacher Education, 44(4), 263-272. https://doi.org/10.1177/0022487193044004004

Creswell, J. W. (2015). A concise introduction to mixed methods research. Thousand Oaks, CA: Sage Publications Inc.

Ferner, B. R. (2013). Elementary Teacher Candidates' Images of Mathematics, Diverse Students, and Teaching: An Exploratory Study With Implications for Culturally Responsive Mathematics Education. Dissertations and Theses. Paper 1097.

Healy, L., \& Hoyles, C. (2000). A study of proof conceptions in algebra. Journal for Research in Mathematics Education, 31 (4), 396-428. https://doi.org/10.2307/749651

Hennink, M. M. (2014). Focus-group discussions. Understanding qualitative research. New York: Oxford University Press. https://doi.org/10.1093/acprof:osob1/9780199856169.001.0001

Hershkowitz, R., \& Vinner, S. (1984). Children's concepts in elementary geometry. A reflection of teacher's concepts? In B. Southwell R. Eyland, M. Cooper, J. Conroy, and K. Collis (Eds.), Proceedings of the 8th PME International Conference 63-69. Darlinghurst, Australia: Mathematical Association of New South Wales.

Jones, K. (2000). Teacher Knowledge and professional development in geometry. Proceedings of the British Society for Research into Learning Mathematics, 20(3), 109-114.

Jones, K. (2002). Issues in the teaching and learning of geometry. In Linda Haggarty (Ed) Aspects of teaching secondary mathematics: perspectives on practice. London: Routledge Falmer

Mashingaidze, S. (2012). The Teaching of Geometric (Isometric) Transformations at Secondary. https://doi.org/10.5539/ass.v8n15p197

Noraini, I. (2006). Teaching and learning of mathematics: Making sense and developing cognitive abilities. Perak: Utusan Publication Sdn. Bhd.

Ponte, J. P., \& Chapman, O. (2006). Mathematics teachers' knowledge and practices. In A. Gutierrez and P. Boero (Eds), Handbook of research on the psychology of mathematics education: Past, present and future. Rotterdam: Sense. 
Rollnick, M., Bennett, J., Rhemtula, M., Dharsey, N., \& Ndlovu, T. (2008). The Place of Subject Matter Knowledge in PCK- A Case Study of South African Teachers Teaching the Amount of Substance and Equilibrium. International Journal of Science Education, 30(10): 1365-1387. Shulman, L. S. (1986.) Those who understand: Knowledge growth in teaching". Educational Researcher, 15(2), 4-14. https://doi.org/10.1080/09500690802187025

School Level: What Approach to Use and Why"? Asian Social Science, 8 (15), 197-210.

Strickland, S. (2008). Unpublished doctoral dissertation, Michigan State University: USA.

Swafford, J. O., Jones, G. A., \& Thornton, C. A. (1997). Increased knowledge in geometry and instructional practice. Journal for Research in Mathematics Education, 28(4), 467-483. https://doi.org/10.2307/749683

Telima, A. (2011). Problems of teaching and learning geometry in secondary schools in Rivers State, Nigeria”. International Journal of Emerging Science, 1(2), 143-152.

Zimbabwe School Examination Council. (2013). 'O' level mathematics examiners' Report 4008/4028: CDU: Harare.

Zimbabwe School Examination Council. (2015). 'O' level mathematics examiners' Report 4008/4028: CDU: Harare. 